\title{
CHARACTERIZATION OF MECHANICAL PROPERTIES AND STUDY OF MICROSTRUCTURES OF FRICTION STIR WELDED JOINTS FABRICATED FROM SIMILAR AND DISSIMILAR ALLOYS OF ALUMINUM
}

Deepa Reddy Akula

Dr.Shefif El-Gizawy, Thesis Supervisor

\begin{abstract}
The objective of this research was to characterize the mechanical properties and study the microstructures of the friction stir welded joints to obtain the optimum process conditions that would result in the desired microstructure and properties for sheet metal formed structures. The joints were tested for mechanical properties such as tensile strength, ductility and formability and the microstructure was studied under optical microscope, scanning electron microscope and energy dispersive spectrograph (EDS). Tests were conducted on a Cincinnati Milling machine which was generously donated by the Boeing Company which was transformed in to a friction stir welding machine by designing and manufacturing the required fixtures.
\end{abstract}

The experiments were designed using response surface methodology (RSM) as the design of experiments, a $L_{9}$ array was designed and the joints fabricated were tested for their mechanical properties and the microstructure was studied to obtain the optimal process conditions. The optimal conditions were identified for friction stir welding of AA 2024-T3, AA 7075-T6 and a combination of both the alloys. 